\title{
A new species of alien terrestrial planarian in Spain: Caenoplana decolorata
}

\author{
Eduardo Mateos ${ }^{\text {Corresp., } 1}$, Hugh D. Jones ${ }^{2}$, Marta Riutort ${ }^{3}$, Marta Álvarez-Presas ${ }^{3,4}$ \\ ${ }^{1}$ Departament de Biologia Evolutiva, Ecologia i Ciències Ambientals. Facultat de Biologia, Universitat de Barcelona, Barcelona, Spain \\ 2 Life Sciences Department, Natural History Museum, London, United Kingdom \\ 3 Departament de Genètica, Microbiologia i Estadística. Facultat de Biologia, Universitat de Barcelona, Barcelona, Spain \\ ${ }^{4}$ School of Biological Sciences, University of Bristol, Bristol, United Kingdom \\ Corresponding Author: Eduardo Mateos \\ Email address: emateos@ub.edu
}

Terrestrial planarians found in a plant nursery in Spain in 2012 are described as a new species, Caenoplana decolorata. Dorsally they are mahogany brown with a cream median line. Ventrally they are pastel turquoise fading to brown laterally. Molecular data indicate that they are a member of the genus Caenoplana, but that they differ from other Caenoplana species found in Europe. One mature specimen has been partially sectioned, and the musculature and copulatory apparatus is described, confirming the generic placement but distinguishing the species from other members of the genus. It is probable that the species originates from Australia. 


\section{A new species of alien terrestrial planarian in Spain: 2 Caenoplana decolorata.}

3

4

5

6

7

12

13

14

15

16

17
Eduardo Mateos ${ }^{1}$, Hugh D. Jones ${ }^{2}$, Marta Riutort ${ }^{3}$, Marta Álvarez-Presas ${ }^{3,4}$.

${ }^{1}$ Departament de Biologia Evolutiva, Ecologia i Ciències Ambientals, Facultat de Biologia, Universitat de Barcelona, Barcelona, Spain.

${ }^{2}$ Life Sciences Department, Natural History Museum, London, UK.

${ }^{3}$ Departament de Genètica, Microbiologia i Estadística, Universitat de Barcelona, Barcelona 08028, Spain.

${ }^{4}$ School of Biological Sciences, University of Bristol, Bristol, BS8 1TQ, UK.

Corresponding author:

Eduardo Mateos ${ }^{1}$

Email: emateos@ub.edu. 
19

20

21

22

23

24

25

26

27

28

29

30

31

32

33

34

35

36

37

38

39

40

41

42

43

44

45

46

47

48

49

50

51

52

53

54

55

56

57

58

59

60

61

62

63

64

\section{Abstract}

Terrestrial planarians found in a plant nursery in Spain in 2012 are described as a new species, Caenoplana decolorata. Dorsally they are mahogany brown with a cream median line. Ventrally they are pastel turquoise fading to brown laterally. Molecular data indicate that they are a member of the genus Caenoplana, but that they differ from other Caenoplana species found in Europe. One mature specimen has been partially sectioned, and the musculature and copulatory apparatus is described, confirming the generic placement but distinguishing the species from other members of the genus. It is probable that the species originates from Australia.

Keywords: alien species-invasive species - land flatworm- molecular identification.

\section{Introduction}

Álvarez-Presas et al. (2014) recorded several terrestrial planarian species from Spain, some considered native to Europe, others introduced from other continents. Some species were identifiable on the basis of external features such as colour and shape, on anatomical characters and comparative molecular analysis. Molecular results suggested that further species were found but at the time they could not be certainly identified to species, though perhaps to genus. This paper describes specimens (Fig. 1, a-d) listed as "Caenoplana Ca2" by Álvarez-Presas et al. (2014). Molecular data (Figure 12 of Álvarez-Presas et al., 2014) indicate that these specimens are of the genus Caenoplana Moseley, 1877, but distinct from other Caenoplana species. One mature specimen has been partially sectioned, and the musculature and copulatory apparatus is described. It has the characters of the genus Caenoplana Moseley, 1877, as amended by Ogren and Kawakatsu (1991) and by Winsor (1991) but differs from other described species of that genus both in external characteristics and anatomy. Neither do the specimens resemble any species described only on external features such as shape and colour and currently placed in the genus Australopacifica Ogren and Kawakatsu 1991, a collective genus containing species "not classifiable into the present taxonomic genera because of insufficient morphological information; geographical distribution largely in Australasia and Indo-Pacific Islands. A collective group for species inquirendae and nomina dubia". It is described as Caenoplana decolorata sp. nov.

\section{Methods}

Sampling

Specimens were collected by E. Mateos from a plant nursery named "vivers casa Paraire" in Bordils municipality (Girona province, Spain, WGS84, position: $42.0348^{\circ} \mathrm{N} ; 2.8986^{\circ} \mathrm{E}$ ). All were collected by hand from beneath pots (Fig. 1e, f) that contained the plants on 12 January 2012 (five specimens: PT426, PT427, PT428, PT430, PT431) and 22 October 2012 (four specimens: PT655, PT657-1, 2 and 3) (Table 1).

Specimens from 12-January-2012 and specimens PT655 and PT657-3 were preserved in absolute ethanol for further molecular analyses. Specimens PT657-1 and 2 were killed with boiling water, fixed with $10 \%$ formalin and preserved in $70 \%$ ethanol. Specimens PT 426 and PT657-1 were photographed alive (Fig. 1).

\section{Molecular methods}


65

66

67

68

69

70

71

72

73

74

75

76

77

78

79

80

81

82

83

84

85

86

87

88

89

90

91

92

93

94

95

96

97

98

99

100

101

102

103

104

105

106

107

108

109

All the sequences used in the present work were obtained in previous studies with the exception of some Cytochrome Oxidase I (herein Cox1) sequences that were obtained from individuals collected at the Real Jardín Botánico de Córdoba (Spain) by Mónica López (Table 1). In all cases, a small section of the anterior end of specimens preserved in absolute ethanol was used for DNA extraction. The new sequences were obtained following the same protocol as in ÁlvarezPresas et al. (2014).

A nucleotide alignment was obtained for the Cox1 sequences based on the AA translation as a guide using BioEdit software (Hall, 1999) and the echinoderm mitochondrial genetic code (9). A Maximum Likelihood (ML) phylogeny was inferred using the IQtree software (Nguyen et al., 2015) with the MFP+MERGE implementation and 10000 replicates for ultrafast bootstrap search (-bb option). Then two single locus molecular species delimitation methods were applied in order to check the validity of the new species presented here and the ones already described and included in the phylogeny. Automatic Barcode Gap Discovery (ABGD) (Puillandre et al., 2012) was the first method performed, implemented in the webpage:

http://wwwabi.snv.jussieu.fr/public/abgd/abgdweb.html. The default parameters were used, selecting initial partitions as they are supposed to be more stable and generally give as a result a closer number of groups described by taxonomists than recursive partitions. The second method applied was the multi-rate Poisson Tree Process (mPTP) analysis (Kapli et al., 2017). The newick tree obtained in the ML phylogenetic inference was used as input in the website http://mptp.h-its.org/\#/tree.

\section{Anatomical methods}

Specimens PT657-1 and 2 were sent to HDJ and are deposited in the Natural History Museum London, accession numbers NHMUK.2014.5.13.12-13. The larger specimen had a visible gonopore, was assumed to be mature and selected for partial sectioning. It was divided into four portions: anterior portion about $2 \mathrm{~cm}$ long not sectioned, in alcohol; pre-pharyngeal section, TS, five slides, two at $15 \mu \mathrm{m}$, three at $10 \mu \mathrm{m}$; posterior portion including pharynx and copulatory apparatus, LS, 16 slides (pharynx separated, HLS) at $15 \mu \mathrm{m}$. Sectioned portions were dehydrated in ethanol and embedded in paraffin wax. Slides were stained in Harris's haematoxylin and eosin and mounted in Canada balsam. The second specimen, about $3.4 \mathrm{~cm}$ long, had no visible gonopore and remains in alcohol.

Colours are expressed as RAL colours (www.ralcolor.com).

The electronic version of this article in Portable Document Format (PDF) will represent a published work according to the International Commission on Zoological Nomenclature (ICZN), and hence the new names contained in the electronic version are effectively published under that Code from the electronic edition alone. This published work and the nomenclatural acts it contains have been registered in ZooBank, the online registration system for the ICZN. The ZooBank LSIDs (Life Science Identifiers) can be resolved and the associated information viewed through any standard web browser by appending the LSID to the prefix http://zoobank.org/. The LSID for this publication is: urn:lsid:zoobank.org:pub:B2636DF8-4372-405C-8A8C4FBEC7396276. The LSID for the new species described is: Caenoplana decolorata sp. nov. urn:lsid:zoobank.org:act:C0CEE92F-A51E-4EDD-B18B-E7F021338667. The online version of this work is archived and available from the following digital repositories: PeerJ, PubMed Central and CLOCKSS. 
110 Figure abbreviations: 1-7, arbitrary regions of the ejaculatory duct (see text); cd, common female 111 duct; gp, gonopore; clm, cutaneous longitudinal muscle; ml, median dorsal line; nc, nerve cord; 112 od, ovovitelline duct; od-cf, opening of ovovitelline ducts to common female duct; plm, 113 parenchymal muscle; rh, rhabdites; sd, sperm duct; $t$, testis.

114

\section{Results}

\section{Molecular results}

117 The final dataset comprises 43 Cox 1 sequences (including 3 outgroups, Table 1), with a final length of $822 \mathrm{bp}$. The resulting ML tree (Fig. 2) shows monophyletic groups comprising 7 putative Caenoplana species. Although the bootstrap values (bb) are not high enough to give support to the relationships between these clades, the monophyly of the new species described here, $C$. decolorata, harbor maximum support. The results of the molecular species delimitation analyses (both mPTP and ABGD) match the same clades present in the phylogeny (Fig. 2) giving rise to 7 putative Caenoplana species. Among them, we find the subject of this study, Caenoplana decolorata.

\section{Taxonomic section}

Order Tricladida Lang, 1884

Suborder Continenticola Carranza, Littlewood, Clough, Ruiz-Trillo, Baguñà and Riutort, 1998

Family Geoplanidae Stimpson, 1857

Subfamily Rhynchodeminae Graff, 1896

Tribe Caenoplaninae Ogren and Kawakatsu, 1991

Genus Caenoplana Moseley, 1877

Caenoplana decolorata new species.

Caenoplana Ca2 Álvarez-Presas et al., 2014.

Etymology: "decolorata" indicating that live specimens resemble C. coerulea but are comparatively pale and discolored.

\section{NHMUK.2014.5.13.12-13}

E. Mateos collection code PT657-1 and PT657-2. Locality: Bordils (Girona, Spain), position N42.0348049 E2.8986153, date 22 October 2012.

Preserved dimensions: holotype (PT657-1): length $46 \mathrm{~mm}$; width $2 \mathrm{~mm}$; height $1 \mathrm{~mm}$; anterior to mouth $28 \mathrm{~mm}$ ( $61 \%$ of body length); anterior to gonopore $39 \mathrm{~mm}(85 \%$ of body length); paratype (PT657-2): length $34 \mathrm{~mm}$; width $2.1 \mathrm{~mm}$; anterior to mouth $17 \mathrm{~mm}(50 \%)$; apparently immature.

All other specimens (with a small section of the anterior end removed) are deposited in the collection of M. Riutort at the University of Barcelona.

\section{External characters}

Live specimens are "mahogany brown" (RAL 8106) with a narrow "cream" (RAL 9001) midline dorsally, merging to "beige brown" (RAL 8024) laterally. The anterior end is "copper brown" (RAL 8004). The ventral mid-line is "pastel turquoise" (RAL 6034) merging into the lateral "beige brown". 
156

157

158

159

160

161

162

163

164

165

166

167

168

169

170

171

172

173

174

175

176

177

178

179

180

181

182

183

184

185

186

187

188

189

190

191

192

193

194

195

196

197

198

199

200

201

Eyes in a sparse uniserial row round the anterior end, biserial for a short distance behind the anterior end and sparse staggered uniserial to the posterior end. Sole nearly the whole of the ventral surface.

\section{Anatomy}

Transverse sections (Fig. 3a) are about $1.3 \mathrm{~mm}$ high and $2 \mathrm{~mm}$ wide. The ciliated creeping sole is about $80 \%$ of the width. The cilia are about $5 \mu \mathrm{m}$ long. The ventral epidermis is a monolayer about $30 \mu \mathrm{m}$ thick and has few rhabdites. Ventral sub-epidermal muscle consists of a layer of circular muscle fibres about $10 \mu \mathrm{m}$ thick and longitudinal muscle in bundles about $30 \mu \mathrm{m}$ thick. Dorsal to the longitudinal muscle bundles is a ventral nerve plexus. There is a distinct, compact layer of parenchymal longitudinal muscle ventrally, 40-50 $\mu \mathrm{m}$ thick, $150 \mu \mathrm{m}$ in from ventral surface. Ventral nerve cords are about $750 \mu \mathrm{m}$ centre to centre, about $120 \mu \mathrm{m}$ in diameter, with transverse commissures. Laterally and dorsally the parenchymal longitudinal muscle is less compact and 10-20 $\mu \mathrm{m}$ thick. Dorsal epidermis is $45 \mu \mathrm{m}$ thick, non-ciliated and has numerous rhabdites. Dorsal and lateral sub-epidermal circular muscle is about $10 \mu \mathrm{m}$ thick, and longitudinal muscle in bundles about $35 \mu \mathrm{m}$ thick. Rhabdites are numerous dorsally and laterally ental to the sub-epidermal muscle, but in the mid-dorsal region, the rhabdites layer is slightly deeper (Fig. 3a, b), presumed to be coincident with the pale midline visible in the living animal.

The retracted cylindrical pharynx occupies the whole length of the pharyngeal pouch and is about $2.5 \mathrm{~mm}$ long, $0.9 \mathrm{~mm}$ in diameter. The pouch is $5.4 \%$ of body length. The pharyngeal aperture is about half way along the pharyngeal pouch. Pharyngeal musculature consists of an outer layer of circular muscle about $10 \mu \mathrm{m}$ thick, a layer of mixed longitudinal and radial muscle about $360 \mu \mathrm{m}$ thick and an inner layer of circular muscle about $30 \mu \mathrm{m}$ thick.

The anterior portion containing the ovaries has not been sectioned. Ovovitelline ducts are about $500 \mu \mathrm{m}$ apart on the inner dorsal surface of the ventral nerve cords (Fig. 3a, d). Vitellaria are not distinguishable with certainty. Their outer and inner diameters are about $25 \mu \mathrm{m}$ and $7 \mu \mathrm{m}$ respectively. They run to about $800 \mu \mathrm{m}$ behind the gonopore, turn dorsally and open into the common female duct about $800 \mu \mathrm{m}$ long which extends forwards with little differentiation to open into the common antrum above the gonopore Fig. $4 \mathrm{a}, \mathrm{c}, \mathrm{e}$ ). There is little or no shell gland tissue surrounding the common female duct.

Testes are numerous, ventral, ovate, about $200 \mu \mathrm{m}$ wide and $300 \mu \mathrm{m}$ high (Fig. 4a, d, e) and run almost to the copulatory apparatus. The sperm ducts cannot be distinguished with certainty in transverse sections. They enter the anterior end of the muscular bulb of the eversible penis, widen slightly and contain small amounts of stored sperm (Fig. 4b). They separately enter the anterior end of the ejaculatory duct which is complex, long and sinuous, about $1.5 \mathrm{~mm}$ from its anterior end to the gonopore (Fig. 4a, b, d, f). It has several regions, for ease of reference they are here arbitrarily numbered 1-7 from anterior to posterior as follows. 1, a small chamber (seminal vesicle) which extends transversely through $10 \times 15 \mu \mathrm{m}$ sections, thus about $150 \mu \mathrm{m}$ wide, the two sperm ducts entering on either lateral extremity. 2, a narrow duct extending posteriorly and turning ventrally and opening into, 3, a sinus-like duct wide laterally, 23 x $15 \mu \mathrm{m}$ thus $345 \mu \mathrm{m}$ wide, but only $35 \mu \mathrm{m}$ in the antero-posterior direction. This duct initially turns ventrally then narrows and curves posteriorly to be almost U-shaped (second arm shorter). The ejaculatory duct continues into, 4 , a narrow sinus-like lumen surrounded by strongly eosinophilic cells forming a structure roughly spherical in outline about $400 \mu \mathrm{m}$ in diameter. The cells of this region appear to be elongate with nuclei mostly adjacent to the lumen (Fig. 4g). This in turn opens into, 5, a portion about $400 \mu \mathrm{m}$ long with sinuous margins, which in turn opens via, 6 , a 
202

203

204

205

206

207

208

209

210

211

212

213

214

215

216

217

218

219

220

221

222

223

224

225

226

227

228

229

230

231

232

233

234

235

236

237

238

239

240

241

242

243

244

245

246

247

small papilla-like opening into 7 , a longer and wider duct about $600 \mu \mathrm{m}$ long with sinuous walls which can be considered to be the male antrum. This in turn opens to the common antrum above the gonopore.

\section{Discussion}

The previous molecular results (Álvarez-Presas et al., 2014) analyzing only Caenoplana sequences (and an outgroup) indicated that $C$. decolorata specimens are closely related to Caenoplana variegata (Fletcher and Hamilton, 1888) (named as C. bicolor (Graff,1899) in that work, see Jones et al., 2020) although without support. In the present work, the tree shows a closer relationship between $C$. decolorata and C. coerulea, while $C$. variegata is sister to the clade formed by these two species (plus some putative unknown species), which will be an expected result having into account the more similar external coloration pattern of the first two species. However, the bb values do not support the relationships among species in the present work neither and make impossible to validate this hypothesis.

The sectioned specimen has multiple eyes, ventral testes, a layer of parenchymal longitudinal muscle, stronger ventrally, a long and fairly elaborate copulatory apparatus, the ejaculatory duct particularly so, and other anatomical characters of the genus Caenoplana Moseley, 1877 as amended by Ogren and Kawakatsu (1991) and by Winsor (1991). Thus we are confident of the generic placement.

However, comparison with other Caenoplana species is problematic. Ogren and Kawakatsu (1991) list 11 species of Caenoplana each with an anatomical description. Winsor (1991) lists 19 species, seven "provisionally placed", within Caenoplana. None of those has a similar external coloration to the present specimens, and the ejaculatory duct of the present specimens is distinctly different to that of any of those 11 . They also differ from C. variegata (Fletcher and Hamilton, 1888) (synonymous with C. bicolor (Graff, 1899), see Jones et al., (2020)).

Winsor (1997) lists a further six numbered, unnamed, Caenoplana species in addition to two named species, C. coerulea coerulea (Moseley, 1877) and C. bicolor (Graff,1899). Winsor (1998) states that 22 Caenoplana species were present in Australia, with no other details.

Presumably this total includes the six numbered, unnamed, species above. Álvarez-Presas et al. (2014) list two further unnamed Caenoplana species, one the subject of this paper. Whether either of these is similar to any of Winsor's (1997) unnamed species is unknown.

In comparing this species to other Caenoplana species or to species placed in the collective genus Australopacifica, particular attention should be made to those with a broadly similar pigment distribution, that is those with, dorsally, a narrow mid-dorsal pale line on an otherwise uniform dark colour (any dark colour) and ventrally with a more or less uniform, but different, colour. The only two species with such a distribution are C. coerulea Moseley, 1877 and C. purpurea (Dendy, 1895).

Caenoplana coerulea Moseley, 1877, originally found in New South Wales, Australia, was described as follows: "Entire body of a dark Prussian blue colour, somewhat lighter on the under surface ... with a narrow, mesial, dorsal, longitudinal stripe of white"; $5 \mathrm{~cm}$ long. Hyman $(1943,1954)$ and Ogren (1989) have described the anatomy of similar specimens found in the USA. This species has distinctly different coloration from the present specimens and the ejaculatory duct has a different structure (Ogren, 1989). It has subsequently been found in New Zealand (Dendy, 1895), several European countries (Álvarez-Presas et al., 2014) and North and South America (Ogren, 1989; Luis-Negrete et al., 2011). 
Geoplana purpurea Dendy, 1895, originally from South Island, New Zealand, was

\section{Acknowledgements}

We thank Mónica López, from the Real Jardín Botánico de Córdoba (Spain), for collecting and supplying some flatworm specimens from Córdoba. HDJ would like to thank The School of Biological Sciences, University of Manchester and Peter Walker of the histology laboratory, for access to facilities.

\section{References}

Álvarez-Presas M, Mateos E, Tudó À, Jones HD, Riutort M. 2014. Diversity of introduced terrestrial flatworms in the Iberian Peninsula: a cautionary tale, PeerJ 2:e430; DOI $10.7717 /$ peerj. $430.35 \mathrm{pp}$.

\section{Carranza S, Littlewood DTJ, Clough KA, Ruiz-Trillo I, Baguñà J, Riutort M. 1998. A} robust molecular phylogeny of the Tricladida (Platyhelminthes: Seriata) with a discussion on morphological synapomorphies. Proceedings of the Royal Society of London, Series $B$ 265:631-640. 
294

295

296

297

298

299

300

301

302

303

304

305

306

307

308

309

310

311

312

313

314

315

316

317

318

319

320

321

322

323

324

325

326

327

328

329

330

331

332

333

334

335

336

337

338

Dendy A. 1895. Additions to the cryptozoic fauna of New Zealand. Annals and Magazine of Natural History Series 6 14:393-401.

Fletcher JJ, Hamilton AG. 1888. Notes on Australian land-planarians, with descriptions of some new species. Part 1. Proceedings of the Linnean Society of New South Wales 2:349374.

Graff L von. 1896. Über die Morphologie des Geschlechtsapparates der Landplanarien. Verhandlungen der Deutschen Zoologischen Gesellschaft 6:75-93.

Graff L von. 1899. Monographie der Turbellarien. II. Tricladia Terricola (Landplanarien). W. Engelmann, Leipzig, 574p, + Atlas, taf. I-LVIII.

Hall TA. 1999. BioEdit: a user-friendly biological sequence alignment editor and analysis program for Windows 95/98/NT. Nucleic Acids Symposium Series 41:95-98. https://doi.org/10.14601/Phytopathol_Mediterr-14998u1.29.

Hyman LH. 1943. Endemic and exotic land planarians in the United States with a discussion of necessary changes of names in the Rhynchodemidae. American Museum Novitates 1241:121.

Hyman LH. 1954. Some land planarians of the United States and Europe, with remarks on nomenclature. American Museum Novitates 1667:1-20.

Jones HD, Mateos E, Riutort M, Álvarez-Presas M. 2020. The identity of the invasive yellowstriped terrestrial planarian found recently in Europe: Caenoplana variegata (Fletcher and Hamilton, 1888) or Caenoplana bicolor (Graff, 1899)? Zootaxa 4731:193-222. https://doi.org/10.11646/zootaxa.4731.2.2.

Kapli P, Lutteropp S, Zhang J, Kobert K, Pavlidis P, Stamatakis A, Flouri T. 2017. Multirate Poisson tree processes for single-locus species delimitation under maximum likelihood and Markov chain Monte Carlo. Bioinformatics 33(11):1630-1638. https://doi.org/10.1093/bioinformatics/btx025.

Lang A. 1884. Die Polycladen (Seeplanarien) des Golfes von Neapel und der angrenzenden Meeresabschnitte. Eine Monographie. Fauna und Flora des Golfes von Neapel 11, R. Friedlander and Sohn, Leipzig, 688 pp. + pls. I-XXXIX.

Luis-Negrete LH, Brusa F, Winsor L. 2011. The blue land planarian Caenoplana coerulea, an invader in Argentina. Revista Mexicana de Biodiversidad 82:287-291.

McDonald JC, Jones HD. 2007. Abundance, reproduction, and feeding of three species of British terrestrial planarians: Observations over 4 years. Journal of Natural History 41:293312. doi: 10.1080/00222930701219149. 
339

340

341

342

343

344

345

346

347

348

349

350

351

352

353

354

355

356

357

358

359

360

361

362

363

364

365

366

367

368

369

370

371

372

Moseley HN. 1877. Notes on the structure of several forms of land planarians, with a description of two new genera and several new species, and a list of all species at present known. Quarterly Journal of Microscopical Science 17:273-292.

Nguyen LT, Schmidt HA, Von Haeseler A, Minh BQ. 2015. IQ-TREE: A fast and effective stochastic algorithm for estimating maximum-likelihood phylogenies. Molecular Biology and Evolution 32(1):268-274. https://doi.org/10.1093/molbev/msu300.

Ogren RE. 1989. Redescription and a new name for the blue land planarian Geoplana vaga Hyman now considered conspecific with Caenoplana coerulea Moseley from Australia (Turbellaria: Tricladida: Geoplanidae). Journal of the Pennsylvania Academy of Science 63:135-142.

Ogren RE, Kawakatsu M. 1991. Index to the species of the family (Turbellaria, Tricladida, Terricola) Part II: Caenoplaninae and Pelmatoplaninae. Bulletin of the Fuji Women's College No. 29, Ser. II:25-102.

Puillandre N, Lambert A, Brouillet S, Achaz G. 2012. ABGD, Automatic Barcode Gap Discovery for primary species delimitation. Molecular Ecology 21(8): 1864-1877. https://doi.org/10.1111/j.1365-294X.2011.05239.x.

Stimpson W. 1857. Prodromus descriptiones animalium evertebratum quae in Expeditione ad Oceanum, Pacificum Septentrionalem a Republica Federata missa, Johnne Rodgers Duce, observavit et descripsit. Proceedings of the Academy of Natural Sciences, Philadelphia 9:1931.

Winsor L. 1991. A provisional classification of Australian terrestrial geoplanid flatworms (Tricladida: Terricola: Geoplanidae). The Victorian Naturalist 108:42-49.

Winsor L. 1997. The biodiversity of terrestrial flatworms (Tricladida; Terricola; Terricola) in Queensland: a preliminary report. Memoirs of the Museum of Victoria 56 (2):575-579.

Winsor L. 1998. The Australian terrestrial flatworm fauna (Tricladida: Terricola). Pedobiologia 42:457-463. 


\section{Table 1 (on next page)}

List of samples used in the molecular analysis with GenBank accession numbers

*Sequences obtained in this study 
1 Table 1. List of samples used in the molecular analysis with GenBank accession numbers.

\section{Species/Morphotype}

\section{Family Geoplanidae \\ Subfamily Rhynchodeminae \\ Tribe Caenoplanini \\ Artioposthia sp. \\ Arthurdendyus testaceus \\ Caenoplana coerulea}

PT1304

PT1305

PT1307

PT1310

Caenoplana sp. 1

Caenoplana sp. 2

Caenoplana sp. 3

Caenoplana sp. 4

Caenoplana variegata

\author{
Australia \\ New Zealand \\ Menorca (Spain) \\ Liverpool, UK \\ El Prat de Llobregat (Barcelona, Spain) \\ Vall de'n Bas (Girona, Spain)
}

Badalona (Barcelona, Spain)

Adelaide (Australia)

Granollers (Barcelona, Spain)

Real Jardín Botánico de Córdoba (Córdoba, Spain)

Victoria (Australia)

Bordils (Girona, Spain)

Southampton, UK

Cardiff, UK

Bordils (Girona, Spain)
GenBank Code

Cox 1

MN990642

MN990643

DQ665961

JQ514564

DQ666030

KJ659617

KJ659618

KJ659619

KJ659620

KJ659622

KJ659623

KJ659624

KJ659626

KJ659633

KJ659634

KJ659642

KJ659645

KJ659647

MT727076*

MT727077*

MT727078*

MT727079*

DQ666031

DQ227621

DQ227625

DQ227627

DQ227634

DQ465372

DQ666032

KJ659648

MN990646

MN990647

MN990648

KJ659628

KJ659629

KJ659630

KJ659631

KJ659632

MN990644

KJ659649

DQ666037

KC608226

FJ969946
Igreginha (Brazil)

Canyamars (Barcelona, Spain)
3 *Sequences obtained in this study 


\section{Figure 1}

Caenoplana decolorata sp. nov.

(a-d) Photographs of live specimens, anterior to the right. (a) Dorsal view of specimen PT426 showing the "mahogany brown" colour and "cream" median line. Scale bar $10 \mathrm{~mm}$. (b) A twisted specimen PT657-1 showing the "pastel turquoise" ventral surface. Scale bar $10 \mathrm{~mm}$. (c) Specimen PT657-1 and (d) specimen PT426, anterior end showing anterior "copper brown" colour and the eyes (the two white lines in (d) are reflections from the lighting). Scale bars $4 \mathrm{~mm}$. (e \& f) pots under which the specimens were found, in a greenhouse (e) and outdoors (f). 


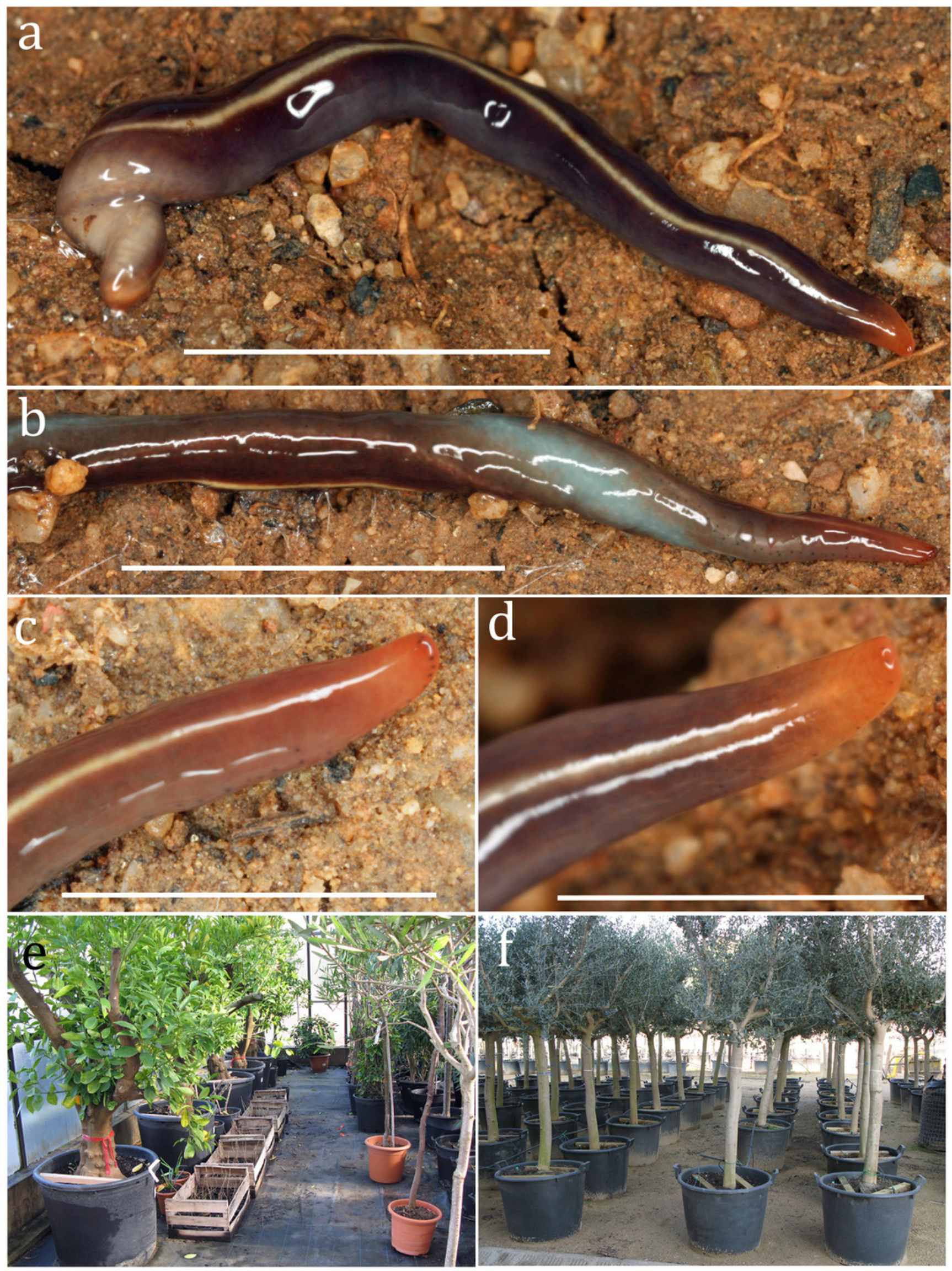


Figure 2

Maximum Likelihood (ML) phylogeny inferred with Cox 1 sequences.

Values at nodes correspond to ultrafast bootstrap replicates (bb) obtained with IQtree software. Vertical bars to the right of the phylogeny correspond to the molecular species delimitation methods results (MPTP, left bar and ABGD, right bar). Scale bar represents number of substitutions per site. Photograph of specimen PT426 in dorsal view (anterior to the right). 


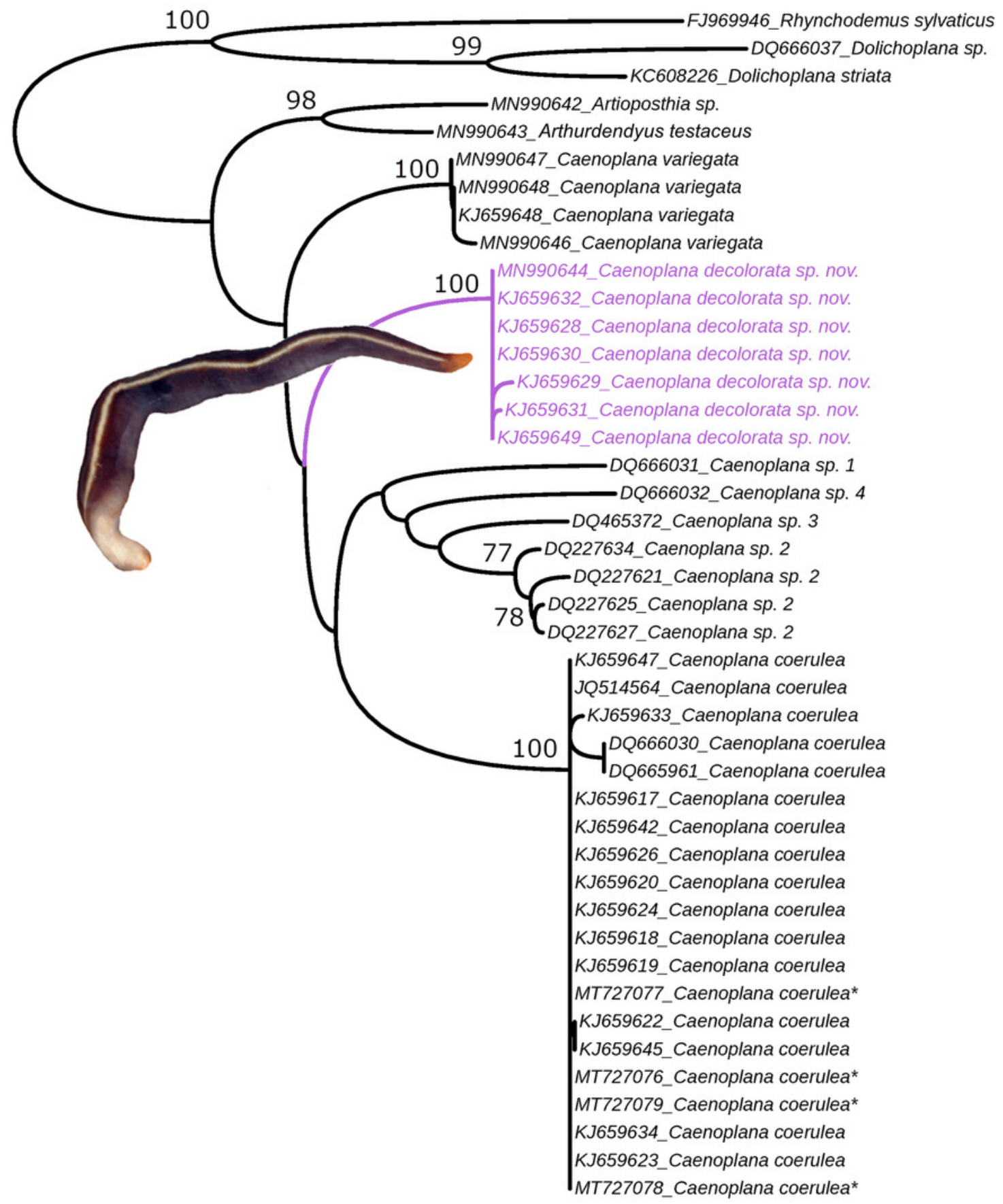

$\begin{array}{cc}\text { M } & \text { A } \\ P & B \\ T & G \\ P & D\end{array}$ 


\section{Figure 3}

Caenoplana decolorata specimen PT657-1 (NHMUK2014.5.13.12).

(a) Entire transverse section $(* *$ indicate the width of the ventral creeping sole; scale line 1 mm). (b) Enlarged mid-dorsal (scale line $100 \mu \mathrm{m}$ ). (c) Enlarged mid-ventral (scale line 100 $\mu \mathrm{m}$ ). (d) The testis, ventral nerve cord and ovovitelline duct on one side (scale line $200 \mu \mathrm{m}$ ). (e) Longitudinal section showing several testes (scale line $250 \mu \mathrm{m}$ ). 

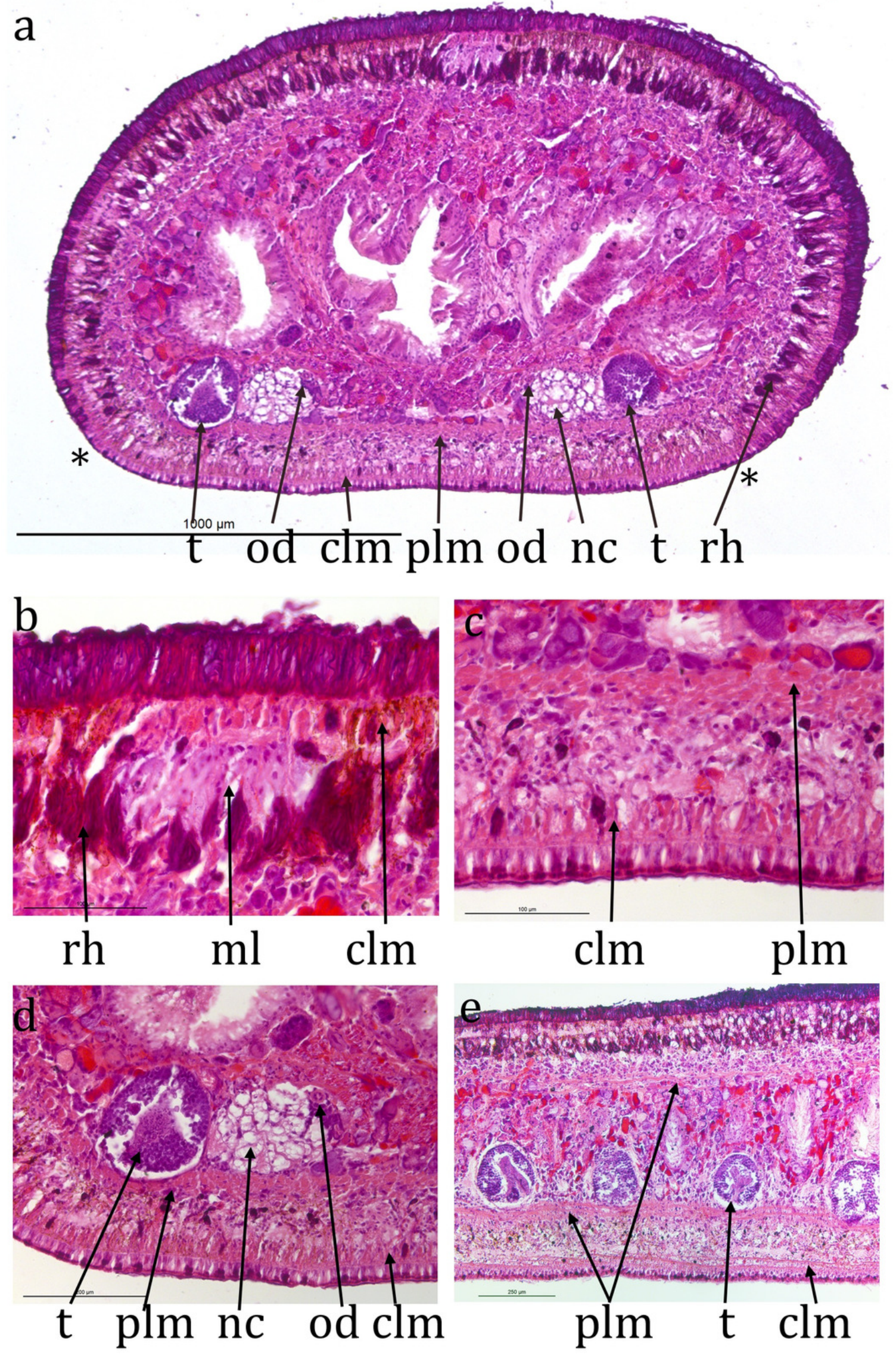


\section{Figure 4}

Caenoplana decolorata specimen PT657-1 (NHMUK2014.5.13.12).

(a) Reconstruction diagram and (d-g) longitudinal sections of the copulatory apparatus (anterior to the left); $a, b$ and $c$ are to the same scale. Micrographs: ( $b \& c)$ Mid-sections through the male and female portions respectively (both folded sections) (scale lines 1000 $\mu m) .(d \& f)$ Further sections through the proximal portion of the male ducts (scale lines 500 $\mu \mathrm{m})$. (e) Section showing the approach of an ovovitelline duct to the common female duct (scale line $500 \mu \mathrm{m}$ ). (g) Enlargement of region 4 of the male duct (scale line $200 \mu \mathrm{m}$ ). The nuclei (cyanophil) are mostly adjacent to the lumen. 

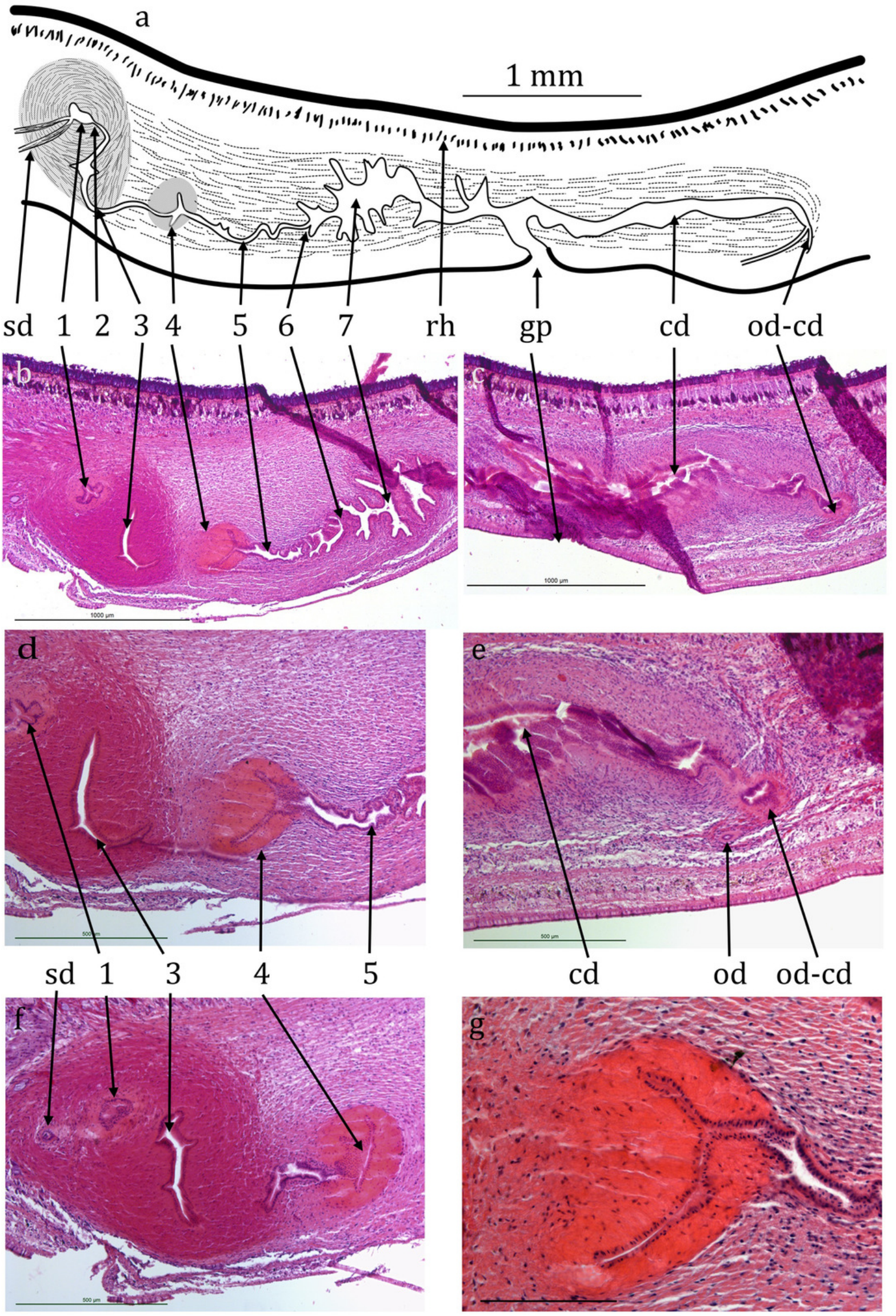